\title{
Evaluation of Ecological Economics in The Context of Ontology, Epistemology and Methodology ${ }^{1}$
}

\author{
Cengizhan Güler (1) ${ }^{2}$
}

Received:15.05.2021; Revised:24.05.2021; Accepted:29.05.2021

\begin{abstract}
There is no clear consensus on what will be the ontological foundations of ecological economics. A similar situation is valid for the epistemologies related to ecological economics and the methodologies to be constructed afterward. In this study, evaluations have been made on the subject area, which tries to contribute from many fundamentals. As a result of the evaluations, it was concluded that instead of subjective judgments about the foundation that is in the process of being formed, the ecological reality dominated by causation can be beneficial for a more effective scientific activity.
\end{abstract}

JEL codes: B41, Q57, P48

Keywords: Ecology, Economics, Philosophy, Economic Methodology

\section{Introduction}

In today's world, economics has become a branch of science that deals with how economies grow, how to makes the most optimal production, and how to distributes wealth, which is the result of economic growth (Stigler, 1975). Another concept, ecology, has the same first syllable as economics, but according to Heraclitus, the last syllable "-logy" points to a set of rules that have always existed in Greek, not created by a creator or humanity. In a combined sense, ecology points to an area-structure in which living things interact together in a certain order. In terms of economics and ecology, we

1 The study was presented as a paper at the International Scientific Research and Innovative Studies Symposium on 23 February.

2 Faculty of Economics, Administrative and Social Sciences, Istanbul Gelisim University, İstanbul, Turkey, email: ceguler@gelisim.edu.tr can say that; In a sense, ecology describes the economics of natural-given households (Faber \& Manstetten, 2009).

When economics and ecology are examined in intellectual foundations by going beyond etymological origins, the first fundamental reality that emerges is this; economics is within the boundaries of ecology. Regardless of which economic system it is, the rules within the economics cannot prevent ecological acceptances and it must continue its existence on the axis of these acceptances. In this context, it can be said that ecology constitutes a greater existential basis than economics.

On this existential basis, the establishment of a methodology of science that is formed on the axis of satisfaction of human activities without taking into account the basic constraint of these activities creates fundamental problems regarding the analy- 
sis. Consumption of limited resources is the backbone of the production. Well, what do the ecological effects that occur as a result of the transformation of this mode of production millions of times mean in terms of economic continuity? Considering the scarcity of resources in mainstream economic theory does not fully meet the dynamics of ecological laws about the structure of the specified continuous process. The dynamics of the post-consumption process are of great importance in terms of evaluating both reality and a sustainable world on a better scientific basis. This important process increases the potential of ecological economics.

In this century, when the climate crisis, which emerged in parallel with the wrong establishment of the relationship between a basic economic activity and ecology, has emerged as an undeniable reality, economies want to continue their locomotives continuously. Our adherence to certain ecological laws requires the transformation of economic activity accordingly and to investigate the compatibility of these laws with our activities. Putting such a constraint in an economic structure whose direction is determined by consumption brings some basic problems, which may result in the revision of market economics rules.

In the plane of this revision process, some questions arise both in this study and in the foundations of general ecological economics. Considering this framework, some questions arise that need to be evaluated. The first question to be questioned is what is the ontological origin of economics and ecology. Another question is whether there is a difference between economics and ecology. Another question that needs to be investigated is whether every material that is economical has to be ecological. The epistemological and methodological connections parallel to the stated questions and their derivatives will also raise various questions within themselves. These inquiries have the potential to create a scientifically beneficial and eclectic process in terms of contributing to the es- tablishment of ecological economics. The scientifically useful and eclectic process, on the other hand, will contribute to the ongoing scientific structure of economics as it is based on a reality that will minimize the normative assumptions on an ontological basis.

In this study, the justifications developed for this potential will be evaluated. The context of the evaluations will be in a critical place to the view that the basis offered by ecological economics, which includes the laws of nature on its ontological basis, together with biophysical processes will cause social change and that only such an axis can be established in ecological economics. In this sense, the scientific justification of ecological laws, which constitute an important part of the developments that will constitute the building blocks of fundamental economics, does not necessitate the change in social structures as a preliminary condition. The strict preconditions set in trying to understand the ontological base in order to maintain or change it undoubtedly contain a limiting epistemology. On the axis of these explanations, the links related to ontology in the first part, epistemological connections in the second part, methodological connections in the third part will be examined and the conclusion part will be discussed.

\section{Literature Review}

Economics has been open to a number of problems since its birth as an intellectual field. In this context, the corpus of the history of economic thought continues its existence by containing both minimal intellectual differences and the schools of thought that are located in fundamentally opposite positions. Although the literature in question offers a very important treasure as a research area when it comes to ecological economics, the studies have been relatively limited.

While entering the discussion, the important point regarding the separation of the concepts of economics and economies from each other is made by Spash (2019) effectively and the economistic fallacy resulting 
from this mistake is opposed. According to the author, while economics appears as a scientific pursuit, economies are a given collection of social realities that emerge at a certain time. In this sense, formal economics may not be able to say anything about a currently given economics. The reason for this is that the ontological structure of given social realities cannot be evaluated singularly. According to Spash, this is the misconception that lies at the basis of the contention of heterodox economists towards mainstream macroeconomists or neo-classical economists. This is because the distinction between formal and substantive economics is divided into singular and plural ontologies.

When the distinction between substantive economics and formal economics is looked at more deeply, factors such as power relations and social structures, which are lacking in the market economics based on the price mechanism, are stated as the main reason why the formal economics in question cannot explain the current economic structure. In this context, comparing ecological economics made by the authors (Gerber \& Scheidel, 2018) with formal economics based on substantive economics seems erroneous according to Spash. The ontological base defined on the basis of the distinction made according to the features specified in the work in question should be a solid understanding of economics combined with a pluralistic ontology based on understanding the wealth of human economies rather than creating single universal economics. In other words, it states that the singular ontology offered by formal economics cannot exist in substantive economics especially in the context of ecological economics.

In addition to the formal and substantive economics discussions, when the realities revealed by Georgescu-Roegen (1971) in his work are examined, the dynamics that occur after the economic process as a situation created by the economic analysis itself are not subject to analysis in modern economics. It remains in place as a solid reality, while it is clear that its absence from the analysis is essentially a deficiency of economic theory. Ecological economics, the idea attempted to be grounded by Georgescu-Roegen, ontologically tries to include the laws of ecology, but by Spash (2011) integrating this solid and biophysical basis into a social change process. In addition to this view da Luz (2011), he stated that the lack of mainstream economists as the first law of the economics is about the distribution of resources in the legal framework in the market, while the second law of the economics is that the economics energy transformation and entropy production determine the growth of wealth. In this context, it seems problematic how to justify such phenomena as the social change process determined by evaluating the same ontological base in different epistemologies.

In this context, as (Spash, 2012) stated in his article, it is also stated that the ontological basis offered by grounding entropy in economics cannot be a source for a pure reductionist epistemology. The present existential basis may include physical, chemical, and biological laws of nature, but as an example, he says that human behavior cannot be understood with this reductionist epistemology. A change is expected when ecological laws are integrated into the economic process, just as the reality presented by natural sciences is defined by humans on an ontological basis and transitioned to epistemology, which is the process of information extraction. While the effect of this change on the human world may have social aspects, it seems problematic to accept change as a pioneer in reality. In this context, the theories that will be formed by basing the theory of economics on an ontological basis in the context of its relations with ecological dynamics can be tested and tested, the more effective theoretical models regarding the answers to ecological problems will be able to offer (Shogren \& Nowell, 1992). 


\section{Ontological Links In The Context of Economics and Ecology}

Scientific knowledge, for which the realities must be the basic indicator, must also manifest itself in economics. The world and vitality, which are a given reality, is a necessary phenomenon for the continuation of economic activity. The criticisms made against the ontological basis of the generally accepted economic theory, beyond the ability to create an objective function given by reality in the tendency to maximize human profits, are generally on the foundations that support understanding rather than explanation in more ambiguous areas. Of course, economics is inherently related to social reality. However, trying to include the ontological definition of these relations into a formal analysis does not help to make an ontology more objective. On the other hand, the narrow profit-maximizing context of economic human rationality provides a conceptual framework in which ecological relations are excluded. Certainly, some presuppositions and abstractions are necessary for the sake of analysis for economics, which is more prone to quantitative analysis in complex human relations than other social sciences. The main point that is wrong is to assume that the result of the analysis made as a result of the epistemology established on the axis of certain axioms in a narrow ontological definition is completely sufficient. When we look at the general reflection of the economic activity of humanity in terms of ecology, which can present pure objectivity, the view that economic activity is understood as active and ecological processes as passive contains ontologically inaccuracies.

Due to its field of existence, ecological economics has to reach the common knowledge of natural sciences and social sciences, as it investigates how economics and ecology function in relation to the relationship between humanity and nature. The association of this existential basis with the normative propositions in the social sciences to ecological economics creates an important problem- atic. Various normative propositions are also proposed for economics, which can be defined from a biophysical basis by affecting the effects of ecological dynamics on the analysis based on classical economic theory (Franco, 2018). In this context, basing a research field specific to a discipline on social utopias, various ethical and ideal evaluations may create various shifts in the reflection of this reality. Ultimately, every science discipline reflects some of the reality (Baumgärtner et al., 2008). The reality that ecological economics is based on should be to accept constraints, which are a kind of necessity as humanity, rather than the basis of ecological boundaries in economics through social utopias.

Ecological economics, which is on a preanalytical basis, is very vulnerable to encountering problems with achieving objectivity on ontological grounds. The factors hindering this objectivity can be either ideology-based or scientifically based. Establishing such a foundation of economic thought essentially has such dynamics (Spash, 2012). Since the ontological basis that can be defined is composed of thoughts in the pre-analytical situation and lacks a specific mathematical and empirical background, it is highly likely that there are some illusions.

In general, economics, which is the first social science to have a formal structure, offers a structure that should be developed in this sense but should not be sacrificed to ambiguous methodologies. The formal structure of neo-classical economics is an important milestone in analyzing the reality that occurs in an economic system in which the market economics and price mechanism operate (Spash, 2019). Ecological realities, on the other hand, play an important role in the expansion of the economic system and transformation of the formal structure into a more robust structure by adding on this touchstone. According to the ontological classification made by Spash (2012), it is categorized as biophysical, social, and economic reality. With ecological dynamics and realities, accepting economic constraints will take prece- 
dence over the social, as economic activity as transformative action will be a more efficient and fundamental variable. Considering that constraints can be created by restricting economic activity socially, some freedom problems arise. The reason for this is that the control of the economy is not only related to the economy but touches many points of life (Hayek, 1976).

Due to the potential basis of ecological economics, the imagination of a systemic change is imposed as an additional burden on ecological economics. To look at economics as a science that will be created by articulating an ontologically observed reality as a must to create new social change damage the essence of the matter. Changes will and should occur when these principles are applied; however, it is insufficient to provide a suitable basis for carrying the belief that all problems will be solved along a utopian axis.

\section{Epistemological Reflections of Eco- logical Economics}

The reason why the modern scientific view is insufficient in the context of ecological economics emerges as an epistemological deficiency in revealing the relation of economics, which is also considered as a social phenomenon, with the objective laws of nature. This shortcoming is not limited to the economics dominated by numerical methods. In sociology, another social science, this deficiency is observed in this field as all reality is socially constructed and evaluations are made with a method aimed at understanding more dominantly. This deficiency comes from the unrationality of human behavior, no doubt. But evaluations in the context of ecological matters that try to link between for instance ecology and economics has to need a different practice of thinking. In this sense, neither method can present a holist structure in the analysis to be made in the relationship between ecology and economics. In short, the epistemological base should parallel both the information provided by the public sphere and the dynamics provided by nature. In a sense, this can be considered as the processing of reality for economics. An epistemology to be considered in this context will present a method in which the truth is confirmed rather than a method based on the compatibility of propositions with other propositions. In this context, in social constructivism, where everything is built on social reality, currents stating that all knowledge is obtained only through empirical processes fall into an epistemic error in essence (Spash, 2012).

It is wrong for this holist approach to put the understanding of a certain discipline at the center. For this reason, researchers in other disciplines, as well as economists, make incomplete evaluations in shaping humans, the most dominant type of the ecosystem, on a sustainable basis. However, the core target of sustainability to correct is economic activity. Sociological, cultural, or ethical considerations, regardless of the dynamics of economic activity, tend to be lacking.

In this sense, although mainstream economic theory accepts that resources are limited and needs are unlimited, it contains deficiencies in terms of ecological process. This acceptance does not contain information despite the dynamics that occur after the use of resources. The laws of nature, which we can see the fact that resources are limited, exhausted, and will eventually be exhausted, are being postponed by technological development in the economics literature. Technological change, which can be evaluated in the context of the dynamism of markets and the creation/sustainability of resources, cannot hide the absolute truth. In this sense, it is necessary to make a resource definition in the light of the existence of absolute entropy law. Because the mainstream economic axioms accept that the resources in question are limited, while distributing the consumption of resources with efficiency, they do not touch on the entropic situation resulting from the transformation of resources. The laws of thermodynamics provide a basis for the existence of biophysical constraints in 
economics rather than a new understanding of economics (Townsend, 1992). These constraints prompt us to look again at the basis of the relationships that economics has established as a science and to examine how economic thought systems are formed around these constraints.

In an order where production and consumption processes are carried out on the axis of resource transformation and entropy is dominant, research to be conducted without entropy dynamics in knowledge inferences is not economically and epistemically optimal. The transformations that have been going on since the beginning of life are under the grip of entropy, including processes in which human beings are not involved. Absolute degradation exists in every activity, and it is impossible to reach a zero entropy level (Georgescu-Roegen, 1971). It is about the size and dynamics of entropy that should be examined here. In his book The Entropy Law and the Economic Process, Roegen examined the process in both philosophical and analytical platforms. The main result is that economic activity should be created within the boundaries provided by nature. Roegen says in his book that economic activity in the context of production-consumption relations consists of only two streams; low entropy producing input and high entropy producing output. Stating that the mode of production that feeds life itself produces low entropy, Georgescu also says that the product that enables people to enjoy life causes high entropy. In this context, economic growth constitutes an irreversible and continuous process that transforms humanity's low entropy into high entropy. In this process, only agriculture and mining operations at a low entropy level. In his interpretation of economic value, the author stated that value can actually be measured by the level of entropy; The value at the low entropy level is zero because the activity at this level is not an activity in which production is based on human pleasure, but an activity related to the continuation of life (Georgescu-Roegen, 1971).
Since the transformation of the boundaries provided by nature also depends on the laws of thermodynamics; this new epistemological foundation, which is formed by taking the laws in question into the integrity of knowledge, can help to create a more scientific structure in order to complete the shortcomings of economics and provide a better understanding of economic growth (Missemer, 2016). According to Missemer, the main purpose of Georgescu's injection of entropy into economics is not economic shrinkage, which is a controversial issue but to create the material dimension of economic development. In this context, an economic shrinkage will certainly occur, but this will be a qualitative change, not a quantitative change. When analyzed on the basis of this distinction, the methodology also differs depending on the epistemological basis. The reality accepted by qualitative change is the manifestation of an economic understanding formed within ecological limits. The point that should be taken into consideration in the name of ecological economics is that the epistemological connection established adheres to the realities on the ontological basis and does not create a kind of epistemic mistake (Spash, 2012). It is predicted that access to information will be more effective in epistemology, which will be created by not breaking away from the ontological base.

\section{Methodological Reflections of Eco- logical Economics}

Even if its ontology and epistemology are well-grounded, the pursuit of the potential of ecological economics coexists with many additional methodological challenges. The merging of society and nature in such a broad framework raises problems of various complexity. In solving such complexity, it is important to be open to other methodologies and to examine their methods of obtaining information. In this context, ecological economics can strengthen the ability to explain interdisciplinary methods open to learning because the field of existence re- 
quires the knowledge of more than one system. Within this domain of existence, there are both precisely defined biophysical processes and social processes that are unclear but where trends can be identified, for example (Franco, 2018). In this sense, when determining the content of the interaction, being open to other disciplines on the methodological basis to be formed should not be considered as method chaos. The conditions under which the effective method in question will be determined should include an eclectic process. In this context, methodological pluralism is not open to an endless understanding of method freedom (Spash, 2012).

Regardless of pluralism, determining the concept of value in the method to be determined methodologically is one of the first striking points in terms of both difficulty and importance. Whether the concept of value can be limited to monetary aggregates presents a key point. At this point, the issue that the value to be attributed to natural resources and vitality cannot be explained by monetary evaluation is dominant. In this context, in the analogy used in the study on the determination of the value of a songbird, he states that the value of the bird in question contains the value in a monetary sense but does not reflect all of its value. By contributing a little to the analogy in question, since every living thing has a share in the survival of life, a living thing may have a value for the system far beyond monetary values, and we may not be able to measure it (Funtowicz \& Ravetz, 1993). The inexplicable value may be faced with the obligation to be understood.

In a methodological sense, what this situation tells us is that the dichotomy between explaining and understanding must be overcome as ecological economics. In essence, a sharp reality emerges here. The necessity of a living thing for the ecosystem is more than making metaphysical evaluations of it. It can be associated with a relatively more objective space in the ambiguous terrain of meaning.

In this sense, different parameters have been proposed for the measurement subject in methodological evaluations. Energy is another criterion proposed as an alternative to today's world economies, where everything is measured in money. In this context, since the evaluation of energy, as the basic criterion will be a physical reductionism, it is highly likely that it will contain a deficiency in reflecting the essence of reality (O'Neill, 2004).

According to (Ehrlich, 1989), an ecologist, in terms of understanding the value of the resources that nature gives to humanity, economists should take into account the roles of physical, chemical, and biological rules governing the actual world in resource consumption. The suggestions whispered by economists in the ears of policymakers constitute the exclusion of such roles. In addition, Ehrlich states that the new ecologyeconomics paradigm, which needs to be established, should give priority to the real order on earth, and that this can be achieved by taking an education in which economics professors are aware of the basic rules of the earth. This education can provide a firsthand contribution to understanding how economic activity is dependent on ecology. This mechanism of understanding can also more effectively embed the value of the ecosystem in the views of economists whispering in policymakers' ears.

\section{Conclusion}

Humanity has enjoyed its freedom in economic activity for a very short time in the time that has passed since the formation of our planet. During this time, without the transformative activity of human beings, vitality continued its activities with ups and downs, within its own rules. One has to realize the reality of these constraints in this regard, eventually. This situation, which every living thing is exposed to as a necessity, is a reality that ecological economics is based on. The set of relationships that this reality is based on is important in terms of being the subject of analysis both in pieces and with interactions within the system, in order to en- 
lighten the aforesaid reality and to create a sustainable basis for the connection between the fundamental laws of the world and economic activity.

In this relationship, a one-way interaction process from ecology to economics is created as a result of considering the opportunities offered by the ecological system as a passive and given factor. In this context, the two-way evaluation of the interactions within the system is essential to increase both the existing ontological basis between economics and ecology and the development of scientific understanding that serves to understand the world on this basis.

Ecological economics, which has great potential because of the answer to how and in what ways the damage to the ecological system will be compensated by the effects such as the ongoing climate crisis, and the objective basis of the foundation of ecological realities in the economics, is in an ongoing phase of ontological, epistemological and methodology. The solid determination of the said ontology will affect epistemology, and the effectiveness of the connection established with epistemology will affect the methodology. There will be traps, ideological views, and subjective evaluations in this process, of course, but each process should be evaluated well both philosophically, economically, and ecologically in order not to move away from the scientific basis of the process. Of course, there are acceptances that the establishment of an ecological economic system requires social. However, these assumptions should not prevent situations that ecological economics will scientifically affect. In this context, the base and axioms that will be formed by not compromising causality and by understanding the boundaries of scientific knowledge will both increase the explanation of the mainstream economic theory and help to justify a greater reality in economics in general.

In this study, examinations and evaluations regarding these processes were made on the basis of not going beyond the boundaries of scientific thought and various suggestions were made in parallel with these. These suggestions summarize the approaching of the existing potential of ecological economics in an objective manner. In this sense, since the grounding of the objective base provided by ecology in economics will provide a relationship with natural sciences, the fact that the point of view does not break from this base prevents the distortion of understanding the ontological structure offered by the scientific ground. Since today's economic theory does not base ecological processes on a theoretical basis, looking at ecological economics with a viewpoint that prioritizes another purpose other than scientific pursuits in eliminating the deficiency in this sense may harm the intended reality. In this context, first of all, the examination of the ontology covered by the objective base, its justification, and the examination of how the dynamics that will emerge will affect the society through economic activity is a more consistent and robust process.

In this context, efforts have been made to contribute in order to establish the link between ecology and economics in an effective and truly sustainable manner. As a result, in the essence of the study, the desire to trigger a social change process by incorporating ecological realities into the economics corpus as a scientific endeavor or its presentation as a necessity was critically evaluated ontologically, epistemologically, and methodologically. The conclusion reached in this context remembers the necessity to approach a scientific reality on its own material basis. In addition, it states that determining the change that the said reality will create as a precondition will harm the potential of ecological economics.

\section{References}

Baumgärtner, S., Becker, C., Frank, K., Müller, B., \& Quaas, M. (2008, oct). Relating the philosophy and practice of ecological economics: The role of concepts, models, and 
case studies in inter- and transdisciplinary sustainability research. Ecological Economics, 67(3), 384-393. Retrieved from https:// doi.org/10.1016\%2Fj. ecolecon. 2008.07.018 doi:10.1016/j.ecolecon.2008.07.018

da Luz, M. G. E. (2011, dec). The second law of economics: Energy, entropy, and the origins of WealthThe second law of economics: Energy, entropy, and the origins of wealth, reiner kümmel, springer, new york, 2011. $\$ 89.95$ (293 pp.). ISBN 978-1-4419-9364-9. Physics Today, 64(12), 5758. Retrieved from https://doi.org/10.1063\% 2Fpt.3.1366 doi:10.1063/pt.3.1366

Ehrlich, P. R. (1989, feb). The limits to substitution: Meta-resource depletion and a new economic-ecological paradigm. Ecological Economics, 1(1), 9-16. Retrieved from https:// doi.org/10.1016\%2F0921-8009\%2889\%2990021-9 doi:10.1016/0921-8009(89)90021-9

Faber, M., \& Manstetten, R. (2009). Philosophical basics of ecology and economy. Routledge. Retrieved from https://doi.org/10.4324\% 2F9780203872192 doi:10.4324/9780203872192

Franco, M. P. (2018, nov). Searching for a scientific paradigm in ecological economics: The history of ecological economic thought, 1880s-1930s. Ecological Economics, 153, 195-203. Retrieved from https:// doi.org/10.1016\%2Fj. ecolecon. 2018.07.022 doi:10.1016/j.ecolecon.2018.07.022

Funtowicz, S. O., \& Ravetz, J. R. (1993). The emergence of post-normal science. In Science, politics and morality (pp. 85-123). Springer Netherlands. Retrieved from https://doi.org/10.1007\%2F978 -94-015-8143-1_6 doi:10.1007/978-94-0158143-1_6

Georgescu-Roegen, N. (1971). The entropy law and the economic process. Harvard University Press. Retrieved from https:// doi.org/10.4159\%2Fharvard. 9780674281653 doi:10.4159/harvard.9780674281653

Gerber, J.-F., \& Scheidel, A. (2018, feb). In search of substantive economics: Comparing today's two major socio-metabolic approaches to the economy - MEFA and MuSIASEM. Ecological Economics, 144, 186-194. Retrieved from https:// doi.org/10.1016\%2Fj.ecolecon. 2017.08.012 doi:10.1016/j.ecolecon.2017.08.012

Hayek, F. (1976). The road to serfdom. Routledge. Retrieved from https://doi.org/10.4324\% 2F9780203991718 doi:10.4324/9780203991718

Missemer, A. (2016, may). Nicholas georgescuroegen and degrowth. The European Journal of the History of Economic Thought, 24(3), 493-506. Retrieved from https:// doi.org/10.1080\%2F09672567.2016.1189945 doi:10.1080/09672567.2016.1189945

O'Neill, J. (2004, may). Ecological economics and the politics of knowledge: the debate between hayek and neurath. Cambridge Journal of Economics, 28(3), 431-447. Retrieved from https://doi.org/10.1093\%2Fcje\% 2F28.3.431 doi:10.1093/cje/28.3.431
Shogren, J. F., \& Nowell, C. (1992, may). Economics and ecology: a comparison of experimental methodologies and philosophies. Ecological Economics, 5(2), 101-126. Retrieved from https:// doi.org/10. 1016\%2F0921-8009\%2892\%2990041-p doi:10.1016/0921-8009(92)90041-p

Spash, C. L. (2011, apr). Social ecological economics: Understanding the past to see the future. American Journal of Economics and Sociology, 70(2), 340-375. Retrieved from https://doi.org/10.1111\%2Fj $.1536-7150.2011 .00777 . x \quad$ doi:10.1111/j.1536$7150.2011 .00777 . \mathrm{x}$

Spash, C. L. (2012, may). New foundations for ecological economics. Ecological Economics, 77, 36-47. Retrieved from https:// doi.org/10.1016\%2Fj.ecolecon. 2012.02.004 doi:10.1016/j.ecolecon.2012.02.004

Spash, C. L. (2019, nov). SEE beyond substantive economics: Avoiding false dichotomies. Ecological Economics, 165, 106370. Retrieved from https://doi.org/10.1016\%2Fj.ecolecon. 2019 .106370 doi:10.1016/j.ecolecon.2019.106370

Stigler, G. J. (1975, oct). The goals of economic policy. The Journal of Law and Economics, 18(2), 283-292. Retrieved from https://doi.org/10 .1086\%2F466813 doi:10.1086/466813

Townsend, K. N. (1992, jul). Is the entropy law relevant to the economics of natural resource scarcity? comment. Journal of Environmental Economics and Management, 23(1), 96-100. Retrieved from https://doi.org/10.1016\%2F0095 -0696\%2892\%2990044-w doi:10.1016/00950696(92)90044-w 